\title{
COLLAGEN XIII AND OTHER ECM COMPONENTS IN THE ASSEMBLY AND DISEASE OF THE NEUROMUSCULAR JUNCTION
}

\author{
Heikkinen Anne ${ }^{1 *}$, Härönen Heli $^{1}$, Norman Oula ${ }^{1}$ and Pihlajaniemi Taina ${ }^{1}$
}

1. Oulu Center for Cell-Matrix Research, Biocenter Oulu, Faculty of Biochemistry and Molecular Medicine, P.O. Box 5400, 90014 University of Oulu, Oulu, Finland

*Correspondence: Heikkinen Anne, address: Oulu Center for Cell-Matrix Research, Biocenter Oulu, Faculty of Biochemistry and Molecular Medicine, P.O. Box 5400, 90014 University of Oulu, Oulu, Finland; telephone: +358 294485 807; fax line +358 8344 064; email address anne.heikkinen@oulu.fi

Abbreviated title: ECM components in NMJ assembly and disease

Acknowledgments: This work was supported by the Academy of Finland (grant 308867 to TP) and the Sigrid Jusélius Foundation.

This article has been accepted for publication and undergone full peer review but has not been through the copyediting, typesetting, pagination and proofreading process which may lead to differences between this version and the Version of Record. Please cite this article as doi: $10.1002 /$ ar. 24092

This article is protected by copyright. All rights reserved. 


\begin{abstract}
Alongside playing structural roles, the extracellular matrix (ECM) acts as an interaction platform for cellular homeostasis, organ development, and maintenance. The necessity of the ECM is highlighted by the diverse, sometimes very serious diseases that stem from defects in its components. The neuromuscular junction (NMJ) is a large peripheral motor synapse differing from its central counterparts through the ECM included at the synaptic cleft. Such synaptic basal lamina (BL) is specialized to support NMJ establishment, differentiation, maturation, stabilization, and function and diverges in molecular composition from the extrasynaptic ECM. Mutations, toxins, and autoantibodies may compromise NMJ integrity and function, thereby leading to congenital myasthenic syndromes (CMSs), poisoning, and autoimmune diseases, respectively, and all these conditions may involve synaptic ECM molecules. With neurotransmission degraded or blocked, muscle function is impaired or even prevented. At worst, this can be fatal. The paper reviews the synaptic BL composition required for assembly and function of the NMJ molecular machinery through the lens of studies primarily with mouse models but also with human patients. In-depth focus is given to collagen XIII, a postsynapticmembrane-spanning but also shed ECM protein that in recent years has been revealed to be a significant component for the NMJ. Its deficiency in humans causes CMS, and autoantibodies against it have been recognized in autoimmune myasthenia gravis (MG). Mouse models have exposed numerous details that appear to recapitulate human NMJ phenotypes relatively faithfully
\end{abstract}


and thereby can be readily used to generate information necessary for understanding and ultimately treating human diseases.

\section{INTRODUCTION}

Synaptic connections between neurons and between nerve and other cell types enable fast, reliable responses to internal and external stimuli. The neuromuscular junction (NMJ) is a cholinergic synapse of the peripheral nervous system between the efferent motoneuron, wrapped by terminal Schwann cells, and a skeletal muscle fiber (Hall and Sanes, 1993, Sanes and Lichtman, 1999). Recent studies have revealed it to feature another cell type, a fibroblast-like one that is poorly characterized at present. This is the kranocyte, which forms a loose cover over the NMJ (Court et al., 2008). At the NMJ, a presynaptic electrical signal originating from the central nervous system (CNS) elicits exocytosis of the neurotransmitter acetylcholine (ACh) from the presynaptic vesicles at active zones. ACh diffuses rapidly through the basal lamina (BL), the extracellular matrix (ECM) of the synaptic cleft, to bind its postsynaptic receptors (AChRs), triggering a cascade of molecular events that leads to contraction of the muscle fiber. Thereupon, ACh signaling is terminated by hydrolysis mediated by ACh esterase (AChE) at the synaptic cleft (Fig. 1A) (Hall and Sanes, 1993, Massoulie and Millard, 2009, Sanes and Lichtman, 1999).

Within the synaptic cleft between the motoneuron terminal and the muscle fiber, a gap approximately 50-80 nm wide, are many synaptic molecules and basement membrane (BM) 
components (Hall and Sanes, 1993, Sanes and Lichtman, 1999). At the synaptic cleft, only the sheet-like BL of the muscle BM, composed of non-fibrillar collagens, non-collagenous glycoproteins, and proteoglycans, passes between the nerve and muscle fiber; the BL further extends into postsynaptic junctional folds (Fig. 1A) (Patton, 2003, Sanes, 2003). The basic core of the BL is composed of collagen IV and laminin networks, interconnected by heparan sulfate proteoglycans and nidogens. Some components of the BL either run throughout the muscle BM (e.g., perlecan, fibronectin, and collagen VI) or display parallel synaptic and extrasynaptic isoforms (type IV collagens, laminins, nidogens, and agrin), while the others (collagen XIII, ColQ, and AChE) exist only synaptically (Bezakova and Ruegg, 2003, M. A. Fox et al., 2007, M. A. Fox et al., 2008, Latvanlehto et al., 2010, Patton et al., 1997, Patton, 2003, Sanes et al., 1990, Sanes, 2003, Singhal and Martin, 2011). Through their presynaptic and postsynaptic cellular receptors, the $\mathrm{BL}$ components serve to attach the nerve terminal and muscle fiber at the $\mathrm{NMJ}$, and errors in operation at any point may lead to misalignment, occupation of the synapse by inappropriate cell types, or (in extreme cases) axon retraction, thereby also compromising postsynaptic integrity. Most synaptic BL components have been further demonstrated to have roles in the biology of the NMJ and to influence its development, maintenance, structure, and function (Massoulie and Millard, 2009, Patton, 2003, Singhal and Martin, 2011). In comparison to CNS synapses, the vertebrate neuromuscular synapses are about 1,000 times larger and are simpler in patterning. They are also easier to access. For these reasons, they are often used in studies of synaptogenesis and synaptic physiology (Desaki and Uehara, 1981, Sanes and 
Lichtman, 2001, Singhal and Martin, 2011). However, study of the motor synapses is highly important in its own right; proper development, maturation, dynamic homeostasis, and functioning of the motor synapse are crucial for many vital processes, among them breathing and voluntary muscle movements. Deficits in NMJ function arising from compromised or lost signaling between the CNS and the skeletal muscle result in myasthenia, with outcomes ranging from mild muscle weakness to lethality due to respiratory failure (Engel et al., 2015, Maselli, Arredondo et al., 2012, Wu et al., 2010).

\section{Formation of the NMJ}

The temporal aspects of NMJ biology can be divided into embryonal development, postnatal maturation, maintenance, and aging (Fig 1 B-C). During embryonal development in mice, two waves of myogenesis take place, at E9.5-E14.5 and E15-E17, resulting in formation of multinucleated myotubes through myoblast fusion. Before innervation, primary myotubes already express diffuse clusters of AChRs at their sarcolemma. Such pre-patterning in, for example, the mouse diaphragm between E12.5 and E13.5 has been posited to act as a primary determinant of the subsequent innervation pattern (Darabid et al., 2014, Lin et al., 2001, Liu et al., 2008, Tintignac et al., 2015, Wu et al., 2010). Multipotent progenitor cells differentiate into motoneurons in the neural tube and to Schwann cells originating in the neural crest. Guided by extracellular cues, motoneurons project their axons toward the developing muscle fibers, with Schwann cells migrating alongside, and in the mouse they reach their targets between E12.5 and E14.5 (Chal and Pourquie, 2017, Sanes and Lichtman, 1999, Tintignac et al., 2015). Those AChR 
clusters that become innervated by motoneurons begin growing in size and develop into NMJs, while aneural clusters will have disappeared by E18.5 (Lin et al., 2001). Though a myotube may initially be innervated by multiple motoneurons, during postnatal maturation muscle fibers become monoinnervated, with the excess axons perishing within two weeks after birth (Fig. 1B) (Darabid et al., 2014, Lin et al., 2001, Liu et al., 2008, Tintignac et al., 2015, Wu et al., 2010).

After prepatterning and innervation, molecules secreted by the nerve, muscle, and Schwann cells contribute to the assembly of the NMJ. These influence the further maturation and functioning of the presynaptic and postsynaptic counterparts. Although NMJs are functional from birth, their properties differ from adult-form NMJs': the maturation required for stable and efficient synapses is complete only postnatally. In this process, the postsynaptic endplate grows larger and undergoes morphological changes, with a simple ovoid shape giving way to complex pretzel-like morphology complemented by junctional folds and gutters. Presynaptically, the terminal branches, active zones, and associated proteins increase in number, and synaptic vesicles accumulate exclusively at the nerve terminal. In mice, the maturation of NMJs is complete approximately one month after birth (Fig. 1C). Over this time, also the motoneuron axons become myelinated and more efficient. Additionally, other functionality changes take place during maturation of NMJs, such as shifts in channel functions in the presynaptic and postsynaptic membranes, further stabilization of AChR clusters, and changes in the composition of the synaptic BL (Sanes and Lichtman, 1999, Sanes and Lichtman, 2001, Shi et al., 2012, Singhal and Martin, 2011, Wu et al., 2010). Interestingly, even the fully mature NMJs in adults 
are not rigid structures but exhibit great plasticity. For example, endurance training has been shown to increase synapse size and complexity along with the extent of motoneuron terminal branching (Deschenes et al., 2006, Deschenes et al., 2016, Nishimune et al., 2014).

\section{Degeneration of the NMJ}

Low levels of physical activity, aging, and disease all impair the morphology of the NMJ, manifesting themselves in partial denervation, fragmentation of AChR clusters, and reductions in active zone and AChR density (Fig. 1B-C) (Li et al., 2011, Nishimune et al., 2014, Punga and Rüegg, 2012, Valdez et al., 2010). In motoneurons affected by degeneration, terminal axons may get thinner or express varicosities indicative of neurofilament accumulations. These changes represent autophagocytosis frequently observed in dystrophic axons in connection with several neurodegenerative diseases (Fig. 1C) (Perrot and Eyer, 2009, Valdez et al., 2010, Yang et al., 2013).

Even though their etiologies differ, all NMJ disorders are characterized by muscle weakness and fatigability resulting from degradation of neurotransmission at the motor synapse. In most cases, the defects are found predominantly in certain muscle groups, preferentially affecting proximal, bulbar, and/or extraocular muscles. Disorders of the NMJ stem from immune-mediated, genetic, or toxic factors. Depending on the molecular complex affected, the pathological processes may be classified as presynaptic, synaptic, or postsynaptic. The two most common NMJ disorders are the autoimmune diseases myasthenia gravis (MG) and Lambert-Eaton 
myasthenic syndrome (LEMS) (Engel et al., 2015, Liang and Han, 2013, Lorenzoni et al., 2012, Souza et al., 2016, Spillane et al., 2010). In the majority of generalized MG cases, the cause is AChR autoantibodies that block ACh binding, thereby inhibiting the opening of the ion channels; decrease AChR levels; and cause complement-mediated damage to the entire endplate (Ha and Richman, 2015). Conversely, most LEMS patients harbor autoantibodies to presynaptic ion channels (Hulsbrink and Hashemolhosseini, 2014).

In addition to the more common diseases, there is a wide and expanding spectrum covering numerous congenital myasthenic syndromes (CMSs) that arise from either recessive or dominant mutations to genes encoding specific proteins of the NMJ, leading to impaired neuromuscular transmission. The most frequent CMS clinical manifestation is early-onset fatigable muscle weakness, although this may not be apparent until adolescence or adulthood. Typically, decrementing of responses in electromyography (EMG) studies demonstrates the patient's NMJ dysfunction. To date, mutations in more than 25 separate genes have been linked to CMSs, of various types (Engel et al., 2015, Hantai et al., 2013, Lee et al., 2018, Rodriguez Cruz et al., 2014a, Rodriguez Cruz et al., 2014b, Souza et al., 2016). Although all CMSs are rare and the diseases' diversity, clinical variability, and diagnostic challenges render prevalence rates difficult to determine with accuracy, the number of confirmed cases among children under 18 years of age in the UK is found approaching 10:1,000,000 (Parr et al., 2014).

Postsynaptic types account for about $75-80 \%$ of CMS cases, while $7-8 \%$ are presynaptic and $14-15 \%$ are of synaptic origin (Lorenzoni et al., 2012). Similarly to MG, most CMSs are 
postsynaptic and involve AChR subunits, taking the form of reduction in AChR number and/or cluster area or changes in channel kinetics that arise from a shorter or prolonged opening time (fast- or slow-channel syndrome, respectively) (Engel et al., 2015, Rodriguez Cruz et al., 2014b, Souza et al., 2016).

Some animal species, among them certain snakes and spiders, produce neurotoxins that paralyze muscles via blocking of ion channels or hyperstimulated/impaired ACh release (Liang and Han, 2013, Souza et al., 2016, Spillane et al., 2010). Medicine derives great benefits from such agents and their modification, but, regrettably, mankind has learned to utilize them as weapons too. One such molecule is $\alpha$-bungarotoxin, a snake polypeptide neurotoxin from Bungarus multicinctus that binds irreversibly to AChRs with high affinity and hence has become an essential tool in NMJ studies, for labeling of postsynaptic endplates (Chang and Lee, 1963, Changeux et al., 1970). On top of information gleaned from human patients, research on mouse models, both spontaneous and purposefully created, has considerably increased our knowledge of the NMJ and advanced the understanding of many human NMJ diseases (Vainzof et al., 2008, Webster, 2018). Owing to the varied etiologies, CMS patients respond differently to a given medication; therefore, all available information helps clinicians to design therapeutic strategies (Lee et al., 2018).

ECM molecules contributing to the assembly of the NMJ and associated diseases The synaptic BL contributes to distinct aspects of NMJ formation, synaptogenesis, and maturation. The topography and ultrastructure are influenced by the synaptic ECM too, alongside 
dynamic homeostasis and transmission. After preliminary alignment of the nerve terminal with prepatterned $\mathrm{AChRs}$ during the embryonic development, $\mathrm{ACh}$ is released into the synaptic cleft through newly formed active zones of presynaptic membranes. In addition to muscle contraction, binding of ACh to AChRs results in destabilization of aneural AChR clusters (Brandon et al., 2003, Lin et al., 2001). By innervation, nerve-derived, large heparan sulfate proteoglycan agrin, deposited in the synaptic BL counteracts the anticlustering effect of ACh (Bolliger et al., 2010, Lin et al., 2001). Agrin promotes AChR clustering through activation of Lrp4, MuSK and its downstream proteins (Fig. 2) (B. Zhang et al., 2008, W. Zhang et al., 2011). Formation of the NMJ clearly depends on agrin: mice lacking agrin fail to properly establish AChR clusters, they show aimless overgrowth of axons, and they do not survive postpartum (Gautam et al., 1996, Lin et al., 2001). Agrin is further capable of inducing postnatal maturation and handling stability of the NMJ later in life (Samuel et al., 2012). Several distinct mutations have been identified in the $A G R N$ gene, causing CMS8 and affecting specific muscle groups with diverse disease pathologies, which can be severe (Huze et al., 2009, Karakaya et al., 2017, Y. Zhang et al., 2017). Interestingly, one of these mutations has been found to cause serious myasthenic symptoms by bringing about molecular characteristics similar to those of non-neural agrin (Maselli, Fernandez et al., 2012). Recently, anti-agrin autoantibodies were identified in both seronegative and seropositive MG patients with early onset and mild to severe clinical presentation, and whether such antibodies are causative remains to be investigated (Cordts et al., 2017). 
$\mathrm{AChE}$, the enzyme terminating neurotransmission at the synapse by hydrolyzing $\mathrm{ACh}$, is primarily embedded in the synaptic BL by a collagenous tail, collagen Q (ColQ; Fig. 2) (Krejci et al., 1997, Tintignac et al., 2015). A ColQ homotrimer binds three AChE tetramers to generate asymmetric $\mathrm{AChE}$, and further connections through perlecan link this complex to dystroglycan, ensuring synaptic localization (Fig. 2) (Kimbell et al., 2004, Krejci et al., 1997, Peng et al., 1999). Perlecan is capable of interacting with several BL components, and through its heparin sulfate side chains it can also bind extracellular signaling molecules (Peng et al., 1999, Talts et al., 1999). In mice, a perlecan deficiency is neonatally lethal, and, interestingly, the NMJs are devoid of AChE although embryonic development of perlecan-null NMJs is otherwise normal (ArikawaHirasawa et al., 2002). Surprisingly, AChE-null mice are outwardly normal at birth. Nevertheless, retarded growth is visible soon after, though NMJs appear ultrastructurally normal when assessed at 12 days postpartum. The NMJs of these mice are extremely sensitive to inhibition of butyrylcholinesterase, a second enzyme capable of ACh hydrolysis, and AChE-null mice die prematurely, before weaning (Xie et al., 2000). A genetic deletion of ColQ in mice results in complete loss of AChE, which extends to globular forms, and butyrylcholinesterase at the NMJ. Still, ColQ-deficient mice are viable at least until weaning (Feng et al., 1999), and together these results demonstrate that there exist additional, although less effective, means of ACh clearance at the NMJ.

Further stabilization of AChE at the NMJ is achieved by ColQ interplay with the Lrp4-MuSK receptor complex, an interaction that contributes also to postsynaptic differentiation (Fig. 2) 
(Cartaud et al., 2004, Karmouch et al., 2013, Sigoillot et al., 2010). In mice, on account of ColQ deficiency AChR clusters increase in density and show reduced size postnatally (Feng et al., 1999, Sigoillot et al., 2010). In addition, some of the NMJs remain immature or become fragmented. Furthermore, subsynaptic cytoplasm exhibits degeneration similar to that found after acute inhibition of AChE, and invagination of Schwann cell processes into the synaptic cleft can be observed (Feng et al., 1999). Tellingly, a decrease in the level of membrane-bound MuSK and an increase in all five AChR subunits leads to a mixture of immature and mature AChR clusters (Sigoillot et al., 2010, Sigoillot et al., 2016). Mutations in COLQ cause CMS5, accounting for about 13\% of CMS cases, and endplate AChE deficiency results (Donger et al., 1998, Engel et al., 2015, Ohno et al., 1998, Ohno et al., 1999). In turn, this leads to prolonged synaptic currents and action potentials, with resultant $\mathrm{AChR}$ desensitization and development of a secondary myasthenic syndrome (Sigoillot et al., 2016).

Inhibition of AChE activity is a front-line treatment for NMJ diseases. AChE inhibitors such as pyridostigmine extend cholinergic transmission by inhibiting hydrolysis of ACh by AChE. This enhances neurotransmission in the synaptic cleft but may also have systemic side effects (Lee et al., 2018, Sieb, 2014). It is noteworthy that, in addition to having medical use, inhibition of AChE is the mechanism of action of a large group of organophosphate compounds that are commonly utilized as pesticides but have also been developed into extremely potent chemical weapons, such as nerve agents sarin and XV (Bailey et al., 2014).

This article is protected by copyright. All rights reserved. 
At the synaptic BL, collagen IV and laminin networks are interconnected by nidogen (Fig. 2) (J. W. Fox et al., 1991). Nidogen-1 is ubiquitous in muscle BMs, while nidogen-2 becomes exclusively synaptic by the third postnatal week in mice (Chiu and Ko, 1994, M. A. Fox et al., 2008). Unexpectedly, a nidogen-2 deficiency has no effect on the distribution of other major synaptic BL proteins. Since nidogen-2 is confined to the synaptic BL only postnatally, concomitant compromising of the postsynaptic architecture occurs no earlier than from P56 onwards in mice lacking it, at which point it is implied by immature and fragmented AChR clusters (M. A. Fox et al., 2008). Interestingly, nidogen-2 was recently found to serve as a target for tetanus toxin binding at the NMJ (Bercsenyi et al., 2014).

Embedded in the synaptic BL are three distinct muscle-derived heterotrimeric isoforms of laminin (laminin 221, 421, and 521, with compositions $\alpha 2 \beta 2 \gamma 1, \alpha 4 \beta 2 \gamma 1$, and $\alpha 5 \beta 2 \gamma 1$, respectively; Fig. 2) (Aumailley et al., 2005, Patton et al., 1997). The laminin $\beta 2$ subunit, present in all synaptic laminins, binds to the extracellular domains of presynaptic voltage-dependent calcium channels (VDCCs) required for ACh release (Nishimune et al., 2004). In laminin $32-$ deficient mice, interaction of this type is lost, preventing maturation of the VDCCs toward P/Qtype (thereby altering calcium-sensitivity) and reducing levels of proteins in the active zone and synaptic vesicle-related proteins (Chand et al., 2015, Chen et al., 2011, M. A. Fox et al., 2007, Nishimune et al., 2004). Consequently, the number of active zones and proximal synaptic vesicles is decreased, resulting in compromised quantal content and a condition resembling LEMS. Moreover, loss of synaptic laminins triggers terminal Schwann cells' invagination into 
the synaptic cleft while also affecting postsynaptic endplates, by reducing the junctional folds (M. A. Fox et al., 2007, Knight et al., 2003, Nishimune et al., 2004, Noakes et al., 1995, Patton et al., 1998). Synaptic laminins contribute to AChR clustering through interactions with their postsynaptic receptors $\alpha 7 \beta 1$ integrin and dystroglycan (Burkin et al., 2000, Jacobson et al., 2001). Integrin $\alpha 3 \beta 1$ has been identified as an additional presynaptic receptor for synaptic laminins (Carlson et al., 2010). Correspondingly, decreased expression of the $\alpha 3$ integrin subunit (null mice die at birth) results in active zone defects as well, along with invagination by Schwann cells, aberrant nerve terminals, and axonal varicosities, together facilitating fragmentation of postsynaptic receptor clusters (Ross et al., 2017). Synaptic laminin-deficient NMJs are comparable to control-group NMJs at birth but display severe defects by the first postnatal week (M. A. Fox et al., 2007, Nishimune et al., 2004, Noakes et al., 1995). Laminin $\beta 2$-deficient mice die in the third week post-birth, through nephrotic deficits, and Pierson syndrome patients carrying $L A M B 2$ mutations phenocopy laminin $\beta 2$-deficient mice; i.e., they suffer from severe CMS in combination with congenital nephrosis (Maselli et al., 2009, Matejas et al., 2010, Noakes et al., 1995).

While total loss of synaptic laminins results in dramatic reduction in active zone number, mice specifically lacking laminin 421 (on account of a genetic deletion of the $\alpha 4$ chain) exhibit misalignment of active zones and consequent defective neurotransmission in adulthood (Chand et al., 2017, Patton et al., 2001). This highlights the role of the molecular network between laminin, VDCCs, and active zone proteins in guiding the synaptic vesicle release sites to be 
directly opposite the crests of the junctional folds and AChRs and in, furthermore, building synaptic vesicles in close proximity to the presynaptic membrane. Laminin 421 is important also in tackling unavoidable degenerative changes wrought by NMJ aging (Samuel et al., 2012).

When all synaptic laminins are lacking, Schwann cells can project into the synaptic cleft. Specifically, laminin 521 has been found to be required for preventing such activity (Patton et al., 1998). While mice deficient in the laminin $\alpha 5$ chain die in early embryogenesis, muscle-specific knockout leads to delayed and incomplete postsynaptic maturation, suggestive of compromised interaction of laminin 521 with the postsynaptic receptor dystroglycan and a deficit in MuSKindependent activation of AChR clustering (Miner et al., 1998, Montanaro et al., 1998, Nishimune et al., 2008). Recently identified loss-of-function mutations in LAMA5 are associated with underdevelopment and dysfunction of nerve terminals, leading to a severe CMS phenotype (Maselli et al., 2017, Maselli et al., 2018). While the $\alpha 4$ and $\alpha 5$ subunits are exclusively synaptic in the muscle, the $\alpha 2$ subunit can be incorporated into extrasynaptic laminin 211 in addition to the synaptic laminin 221, and mutations in its gene result in congenital muscular dystrophy both in mice and in man (Miyagoe-Suzuki et al., 2000). The disease additionally features NMJ defects specifically affecting postsynaptic maturation (Gilbert et al., 1973, Law et al., 1983).

Collagen IV exists in the synaptic BL as three heterotrimeric combinations of $\alpha$ chains $\left(\alpha 1_{2} \alpha 2\right.$, $\alpha 3 \alpha 4 \alpha 5$, and $\alpha 5_{2} \alpha 6$; Fig. 2). Collagen IV $\left(\alpha 1_{2} \alpha 2\right)$ is found throughout muscle BMs from embryonic stages onward and is not specific to motor synapses (Sanes, 2003). Studies with mutant mice imply that collagen IV $\left(\alpha 1_{2} \alpha 2\right)$ is necessary for the accumulation of synaptic 
vesicles both during the embryonic development and postnatally but becomes dispensable at three weeks of age. In contrast, collagen IV $(\alpha 3 \alpha 4 \alpha 5)$ and $\left(\alpha 5_{2} \alpha 6\right)$ are expressed synaptically from the third postnatal week onward, after which mice with collagen $\alpha 5$ (IV) chain deficiency wherein both collagen IV $(\alpha 3 \alpha 4 \alpha 5)$ and $\left(\alpha 5_{2} \alpha 6\right)$ heterotrimers are absent develop various presynaptic and axonal defects. These include axon retraction from the postsynaptic specializations, preterminal ring-like neurofilament aberrations, and axonal expansion. Collagen IV of these two varieties is important also for postsynaptic integrity: a collagen $\alpha 5(\mathrm{IV})$ chain deficiency results in fragmentation of the AChR-rich endplate (M. A. Fox et al., 2007).

A very recent study newly identified collagen VI, an abundant muscle BM-associated heterotrimeric collagen whose deficiency results in muscular dystrophies, as an important component of the NMJ (Fig. 2). A deficiency of collagen VI in null mice and human patients leads to defects in the postsynaptic endplate, as well as errors in expression of synaptic molecules, and compromised neurotransmission when studied in null mice. In vitro studies of $\mathrm{C} 2 \mathrm{C} 12$ myotubes found collagen VI to regulate synaptic transcription as well as AChR clustering (Cescon et al., 2018).

Distinct phenotypes, with varying severity, in both mutant mice and human patients highlight several unique and indispensable roles of various NMJ proteins. Each piece in the synaptic BL structure has a part to play for achieving full assembly and functioning of the neuromuscular system.

This article is protected by copyright. All rights reserved. 


\section{Collagen XIII in focus}

While only a single common ancestor, COL-99, exists in Caenorhabditis elegans, in mammals together with closely related collagens XXIII and XXV, collagen XIII share a subfamily of membrane-associated collagens with interrupted triple helices (MACITs) (Tu et al., 2015). These non-fibrillar collagens are type II transmembrane proteins with a short N-terminal intracellular domain, a single membrane-spanning hydrophobic domain, and a large extracellular C-terminal domain that can be shed into the pericellular environment through the action of furin-type proprotein convertases (Fig. 2) (Banyard et al., 2003, Hägg et al., 1998, Hashimoto et al., 2002, Väisänen et al., 2004, Veit et al., 2007).The presence of two distinct molecular forms of these collagens points to the possibility of multiple roles as cellular receptors or ECM components and soluble signaling molecules. In immunoelectron microscopy of the NMJ, collagen XIII associates with the synaptic BL and postsynaptic sarcolemma, and immunofluorescent staining shows it is being confined to synaptic expression (in the muscle, a second dedicated location of collagen XIII is the myotendinous junction) (Hägg et al., 2001, Härönen et al., 2017, Latvanlehto et al., 2010). Neither type XIII nor type XXV collagen is detectable in cultured C2C12 myoblast cells, while the expression of both is strongly induced after fusion into myotubes (Latvanlehto et al., 2010, Tanaka et al., 2014). At protein level, both the transmembrane form and shed collagen XIII were confirmed to be present in cultured myotubes, and marker staining utilizing $\beta$ galactosidase activity in $\operatorname{Coll} 3 a 1^{\mathrm{LacZ}}$ mice verified the expression to be muscle-derived 
(Latvanlehto et al., 2010). Collagen XIII may interact with several BL components, since its ectodomain has been shown in vitro to bind with high affinity to heparin, perlecan, nidogen-2, and fibronectin and with intermediate affinity to collagen IV and laminin (Fig. 2) (Tu et al., 2002).

Animal studies have clarified the roles of MACITs in the peripheral nervous system. COL-99 mutant worms display an axon pathfinding defect for ventral nerve cord motor nerves (Taylor et al., 2018). During worms' development, COL-99 is expressed in the hypodermis, and in adult worms it is expressed in muscle and the NMJ, suggesting a cell non-autonomous paradigm in axon guidance (Taylor et al., 2018, Tu et al., 2015). Interestingly, collagen XIII ectodomain support was found to enhance neurite outgrowth in cultured rat fetal hippocampal neurons (Sund et al., 2001). Moreover, knockout studies have determined collagen XXV to be indispensable to embryonal intramuscular innervation in mice. Although motoneuron axons in these studies initially projected properly toward the muscle targets, they failed to elongate and branch intramuscularly. Axon degeneration resulted, and the insufficient supply of target-derived survival factors led to total motoneuron loss by E18.5. Muscle development was compromised, and together these defects led to respiratory failure and neonatal lethality (Tanaka et al., 2014). In consistent findings, mutations in the COL25A1 gene are associated with human diseases affecting innervation of cranial muscles, especially extraocular ones (Khan and Al-Mesfer, 2015, Shinwari et al., 2015). The possibility of a link between collagen XXIII and the NMJ or diseases thereof awaits confirmation.

This article is protected by copyright. All rights reserved. 
Recently, anti-collagen XIII antibodies were identified in MG patients, although their possible involvement in the disease's emergence remains enigmatic (Tu et al., 2018). Genetically, collagen XIII is linked to NMJ disease in that loss-of-function mutations in COL13A1 have been proven to cause CMS19. Of 15 CMS patients without a known etiology, Logan and colleagues identified three patients harboring two separate mutations in the COL13A1 gene, and additional mutations have been reported since, though not yet specified (Beeson et al., 2018, Logan et al., 2015). Clinically, a collagen XIII deficiency in these homozygous and compound heterozygous patients caused weakness of bulbar, axial, and limb muscles especially. Feeding and breathing problems emerged soon after birth. Notwithstanding the severely compromised muscle function, few signs of regeneration was observed in the muscle morphology in analysis at 6-12 months of age - namely, some centrally located nuclei, slightly variable fiber size, and the presence of fetal myosin (Logan et al., 2015). Collagen XIII-deficient mice closely phenocopy many of the symptoms displayed by CMS19 patients. For example, muscle weakness is obvious in null mice in that they are able to hold their body weight for only about one minute while wild-type littermate control mice performed successfully in a grid hanging test until the five-minute cutoff time (Härönen et al., 2017, Zainul et al., 2018). Furthermore, the muscle pathology of young adult null mice shows regeneration alterations identical to those in the patient samples examined. Mouse studies reveal also that, specifically, slow muscle fibers are susceptible to regeneration changes stemming from lack of collagen XIII, with a shift toward faster fiber types being observed in null mice (Härönen et al., 2017).

This article is protected by copyright. All rights reserved. 
Additional features typical of affected individuals include low-set ears, micrognathia, a higharched palate, barrel chest (pectus carinatum), and recurrent chest infections. It is noteworthy in this connection that the severe respiratory-muscle weakness and chronic lung disease caused the death of one patient at the age of eight years (Logan et al., 2015). In null mice, however, the NMJ defects stabilize in adulthood and the myasthenia is not progressive (Zainul et al., 2018). Because collagen XIII is not purely NMJ-specific - it has been found to be expressed in nearly all tissues studied - it is not so surprising that collagen XIII-deficient mice occasionally experience failure in their general condition before senescence, indicating that other organ systems may be involved in the disease etiology as well (Hägg et al., 2001, Sund et al., 2001, Zainul et al., 2018). This is typical also for many other diseases affecting the NMJ, since molecules affected in a given condition may be components of BMs elsewhere in the body too.

To explore the connection between collagen XIII and CMS19 pathology further, Logan and colleagues confirmed loss of the collagen in the NMJ from a patient sample taken at six months of age. Additional immunostainings of cryosections have indicated a normal pattern of expression of proteins marking synaptic vesicles, terminal Schwann cells, AChE, and AChRs (Logan et al., 2015); however, this stands in contrast to what is visible in both young and adult null mice - for example, AChR cluster size and complexity are compromised from two weeks of age onward (Härönen et al., 2017, Latvanlehto et al., 2010). In vitro studies involving C2C12 myotubes suggest that the shed collagen XIII ectodomain is capable of inducing AChR cluster maturation and, on the other hand, that expression of mutant collagen XIII mimicking the 
COL13A1 frameshift mutation reduces the number of large AChR clusters while not having an effect on average AChR cluster size (Latvanlehto et al., 2010, Logan et al., 2015). These studies suggest that collagen XIII conducts some direct autocrine functions in the AChR clustering. In addition, postsynaptic defects detected in adult null mice may result in large part from alterations in retrograde signaling actions: a collagen XIII deficiency has very strong effects on presynaptic alignment, differentiation, complexity, integrity, and function (Härönen et al., 2017, Latvanlehto et al., 2010). Mouse samples were stained for synaptic markers in a whole-mount setting, which afforded 3D evaluation of the NMJs better than did the patient-sample preparation, from a frozen muscle biopsy. Staining revealed that accumulation of synaptic vesicles exclusively at the nerve terminal is delayed in young adult null mice; accordingly, vesicles can be erroneously found in the terminal axon. Furthermore, innervation is incomplete; the postsynaptic receptors are not fully covered by their presynaptic counterparts, and Schwann cells invaginate into the synaptic cleft on account of compromised transsynaptic adhesion (Latvanlehto et al., 2010). Terminal branching complexity is reduced, retraction of nerve termini and Schwann cells from the synapse can be observed, and axons show signs of degeneration (Härönen et al., 2017, Zainul et al., 2018). Moreover, a reduction in the number of synaptic vesicles and of active zones consistently leads to compromised amplitude of postsynaptic potentials, probabilities of spontaneous release and a readily releasable pool of ACh in ex vivo electrophysiological measurements (Latvanlehto et al., 2010). Mouse studies show additionally that transmembrane collagen XIII is sufficient for propagating normal adhesion between synaptic partners, for which $\alpha 1 \beta 1$ integrin possibly could 
serve as a direct receptor on the presynaptic membrane (Härönen et al., 2017, Martin et al., 1996, Nykvist et al., 2000). Mice with forced expression of transmembrane collagen XIII and no shed form display NMJs that are closer to normal than those of null mice, indicating that it is the transmembrane form that has primary responsibility for many of the collagen XIII actions at the NMJ, although its shedding into the synaptic BL is also indispensable (Härönen et al., 2017, Zainul et al., 2018).

In addition to the postsynaptic and presynaptic alterations detected in collagen XIII-null mice, disturbances in the synaptic AChE pattern were found. AChE does not align precisely with AChRs in null mice as it does in control mice; instead, there are receptor-positive areas devoid of $\mathrm{AChE}$ and vice versa; $\mathrm{AChE}$ diffuses from the AChR cluster area. Consistently, ColQ has been added to the list of BL components interacting with collagen XIII and thereby stimulating AChE fine localization at the NMJ in a collagen XIII-dependent manner (Härönen et al., 2017).

The results presented above attest that collagen XIII plays an important role in postnatal maturation of presynaptic, synaptic, and postsynaptic constituents of the NMJ. The significance of collagen XIII has been studied further in the context of regeneration of the NMJ after peripheral nerve injury. With collagen XIII-null mice, whole-mount immunofluorescent staining and function tests determined that reestablishment of the NMJs is delayed and remains incomplete. The muscle morphology meanwhile is unaltered in null mice from before injury to the end of the follow-up time, six weeks post-injury. Motor axons display delays in regenerative processes, a defected pattern existing before the injury occurred. These elements compromise 
reestablishment and stabilization of the $\mathrm{NMJ}$ and point to a fundamental role of collagen XIII in recreation of the motor synapse after peripheral nerve injury. This finding suggests also that healing of a nerve injury in a CMS19 patient might stay incomplete (Zainul et al., 2018).

Studies with mouse models have dramatically increased knowledge of the functions of collagen XIII and of the pathological consequences of its altered expression. Furthermore, 3,4Diaminopyridine, a substance used for successfully treating one CMS19 patient produced shortterm improvements in the muscle strength of collagen XIII-deficient mice, providing more evidence that null mice may have use also as a preclinical model in preliminary evaluation of possible treatment options for CMS19 patients (Härönen et al., 2017).

\section{SUMMARY}

Molecules specific to the synaptic BL operate alongside more widely distributed fundamental muscle BM components to form the indispensable platform that optimal neurotransmission demands. The presentation of NMJ disorders varies in response to numerous distinct factors behind disease etiologies. For that reason, responses to medication may be unpredictable in cases where the causative disease mechanism is not well characterized. Although conditions affecting the NMJ are relatively rare, any knowledge that can contribute to improved treatment is of great importance for patients. Mouse models have proven reliable and informative in studies of the molecular architecture and functionality aspects of the NMJ components. They thereby aid in predicting and planning treatment options, and these models can assist us still further, aiding 
with preclinical testing of such strategies. It is, however, important to keep in mind differences in certain features of the NMJ between species when translating findings from mouse to human (Jones et al., 2017). Underlying factors in NMJ diseases are being newly identified continuously, and the results accumulated add to our understanding of the formation process and functioning of the NMJ. All such research results facilitate recognition and diagnosis of NMJ disorders, of whatever sort, and contribute to treatment that can ameliorate the suffering of human patients.

\section{REFERENCES}

Arikawa-Hirasawa E, Rossi SG, Rotundo RL, Yamada Y. 2002. Absence of acetylcholinesterase at the neuromuscular junctions of perlecan-null mice. Nat Neurosci 5:119-123.

Aumailley M, Bruckner-Tuderman L, Carter WG, Deutzmann R, Edgar D, Ekblom P, Engel J, Engvall E, Hohenester E, Jones JC, Kleinman HK, Marinkovich MP, Martin GR, Mayer U, Meneguzzi G, Miner JH, Miyazaki K, Patarroyo M, Paulsson M, Quaranta V, Sanes JR, Sasaki T, Sekiguchi K, Sorokin LM, Talts JF, Tryggvason K, Uitto J, Virtanen I, von der Mark K, Wewer UM, Yamada Y, Yurchenco PD. 2005. A simplified laminin nomenclature. Matrix Biol 24:326-332.

Bailey AM, Baker SN, Baum RA, Chandler HE, Weant KA. 2014. Being prepared: emergency treatment following a nerve agent release. Adv Emerg Nurs J 36:22-33.

Banyard J, Bao L, Zetter BR. 2003. Type XXIII collagen, a new transmembrane collagen identified in metastatic tumor cells. J Biol Chem 278:20989-20994.

Beeson D, Cossins J, Rodriguez-Cruz P, Maxwell S, Liu WW, Palace J. 2018. Myasthenic syndromes due to defects in COL13A1 and in the N-linked glycosylation pathway. Ann N Y Acad Sci 1413:163-169.

Bercsenyi K, Schmieg N, Bryson JB, Wallace M, Caccin P, Golding M, Zanotti G, Greensmith L, Nischt R, Schiavo G. 2014. Tetanus toxin entry. Nidogens are therapeutic targets for the prevention of tetanus. Science 346:1118-1123.

Bezakova G, Ruegg MA. 2003. New insights into the roles of agrin. Nat Rev Mol Cell Biol 4:295-308. 
Bolliger MF, Zurlinden A, Luscher D, Butikofer L, Shakhova O, Francolini M, Kozlov SV, Cinelli P, Stephan A, Kistler AD, Rulicke T, Pelczar P, Ledermann B, Fumagalli G, Gloor SM, Kunz B, Sonderegger P. 2010. Specific proteolytic cleavage of agrin regulates maturation of the neuromuscular junction. J Cell Sci 123:3944-3955.

Brandon EP, Lin W, D'Amour KA, Pizzo DP, Dominguez B, Sugiura Y, Thode S, Ko CP, Thal LJ, Gage FH, Lee KF. 2003. Aberrant patterning of neuromuscular synapses in choline acetyltransferase-deficient mice. J Neurosci 23:539-549.

Burkin DJ, Kim JE, Gu M, Kaufman SJ. 2000. Laminin and alpha7beta1 integrin regulate agrin-induced clustering of acetylcholine receptors. J Cell Sci 113 ( Pt 16):2877-2886.

Carlson SS, Valdez G, Sanes JR. 2010. Presynaptic calcium channels and alpha3-integrins are complexed with synaptic cleft laminins, cytoskeletal elements and active zone components. J Neurochem 115:654-666.

Cartaud A, Strochlic L, Guerra M, Blanchard B, Lambergeon M, Krejci E, Cartaud J, Legay C. 2004. MuSK is required for anchoring acetylcholinesterase at the neuromuscular junction. J Cell Biol 165:505-515.

Cescon M, Gregorio I, Eiber N, Borgia D, Fusto A, Sabatelli P, Scorzeto M, Megighian A, Pegoraro E, Hashemolhosseini S, Bonaldo P. 2018. Collagen VI is required for the structural and functional integrity of the neuromuscular junction. Acta Neuropathol.

Chal J, Pourquie O. 2017. Making muscle: skeletal myogenesis in vivo and in vitro. Development 144:2104-2122.

Chand KK, Lee KM, Lavidis NA, Noakes PG. 2017. Loss of laminin-alpha4 results in preand postsynaptic modifications at the neuromuscular junction. FASEB J 31:13231336.

Chand KK, Lee KM, Schenning MP, Lavidis NA, Noakes PG. 2015. Loss of beta2-laminin alters calcium sensitivity and voltage-gated calcium channel maturation of neurotransmission at the neuromuscular junction. J Physiol 593:245-265.

Chang CC, Lee CY. 1963. Isolation of neurotoxins from the venom of bungarus multicinctus and their modes of neuromuscular blocking action. Arch Int Pharmacodyn Ther 1:241-257.

Changeux JP, Kasai M, Lee CY. 1970. Use of a snake venom toxin to characterize the cholinergic receptor protein. Proc Natl Acad Sci U S A 67:1241-1247.

Chen J, Billings SE, Nishimune H. 2011. Calcium channels link the muscle-derived synapse organizer laminin beta2 to Bassoon and CAST/Erc2 to organize presynaptic active zones. J Neurosci 31:512-525.

Chiu AY, Ko J. 1994. A novel epitope of entactin is present at the mammalian neuromuscular junction. J Neurosci 14:2809-2817.

Cordts I, Bodart N, Hartmann K, Karagiorgou K, Tzartos JS, Mei L, Reimann J, Van Damme P, Rivner MH, Vigneron A, Weis J, Schulz JB, Tzartos SJ, Claeys KG. 2017. Screening for lipoprotein receptor-related protein 4-, agrin-, and titin-antibodies and exploring the autoimmune spectrum in myasthenia gravis. J Neurol 264:1193-1203.

This article is protected by copyright. All rights reserved. 
Court FA, Gillingwater TH, Melrose S, Sherman DL, Greenshields KN, Morton AJ, Harris JB, Willison HJ, Ribchester RR. 2008. Identity, developmental restriction and reactivity of extralaminar cells capping mammalian neuromuscular junctions. J Cell Sci 121:3901-3911.

Darabid H, Perez-Gonzalez AP, Robitaille R. 2014. Neuromuscular synaptogenesis: coordinating partners with multiple functions. Nat Rev Neurosci 15:703-718.

Desaki J, Uehara Y. 1981. The overall morphology of neuromuscular junctions as revealed by scanning electron microscopy. J Neurocytol 10:101-110.

Deschenes MR, Kressin KA, Garratt RN, Leathrum CM, Shaffrey EC. 2016. Effects of exercise training on neuromuscular junction morphology and pre- to post-synaptic coupling in young and aged rats. Neuroscience 316:167-177.

Deschenes MR, Tenny KA, Wilson MH. 2006. Increased and decreased activity elicits specific morphological adaptations of the neuromuscular junction. Neuroscience 137:1277-1283.

Donger C, Krejci E, Serradell AP, Eymard B, Bon S, Nicole S, Chateau D, Gary F, Fardeau M, Massoulie J, Guicheney P. 1998. Mutation in the human acetylcholinesteraseassociated collagen gene, COLQ, is responsible for congenital myasthenic syndrome with end-plate acetylcholinesterase deficiency (Type Ic). Am J Hum Genet 63:967975.

Engel AG, Shen XM, Selcen D, Sine SM. 2015. Congenital myasthenic syndromes: pathogenesis, diagnosis, and treatment. Lancet Neurol 14:461-4422(15)00010-1. Epub 2015 Mar 26.

Feng G, Krejci E, Molgo J, Cunningham JM, Massoulie J, Sanes JR. 1999. Genetic analysis of collagen Q: roles in acetylcholinesterase and butyrylcholinesterase assembly and in synaptic structure and function. J Cell Biol 144:1349-1360.

Fox JW, Mayer U, Nischt R, Aumailley M, Reinhardt D, Wiedemann H, Mann K, Timpl R, Krieg T, Engel J. 1991. Recombinant nidogen consists of three globular domains and mediates binding of laminin to collagen type IV. EMBO J 10:3137-3146.

Fox MA, Ho MS, Smyth N, Sanes JR. 2008. A synaptic nidogen: developmental regulation and role of nidogen-2 at the neuromuscular junction. Neural Develop 3:24.

Fox MA, Sanes JR, Borza DB, Eswarakumar VP, Fassler R, Hudson BG, John SW, Ninomiya Y, Pedchenko V, Pfaff SL, Rheault MN, Sado Y, Segal Y, Werle MJ, Umemori H. 2007. Distinct target-derived signals organize formation, maturation, and maintenance of motor nerve terminals. Cell 129:179-193.

Gautam M, Noakes PG, Moscoso L, Rupp F, Scheller RH, Merlie JP, Sanes JR. 1996. Defective neuromuscular synaptogenesis in agrin-deficient mutant mice. Cell 85:525-535.

Gilbert JJ, Steinberg MC, Banker BQ. 1973. Ultrastructural alterations of the motor end plate in myotonic dystrophy of the mouse (dy2J dy2J). J Neuropathol Exp Neurol 32:345-364.

This article is protected by copyright. All rights reserved. 
Ha JC, Richman DP. 2015. Myasthenia gravis and related disorders: Pathology and molecular pathogenesis. Biochim Biophys Acta 1852:651-657.

Hägg P, Rehn M, Huhtala P, Väisänen T, Tamminen M, Pihlajaniemi T. 1998. Type XIII collagen is identified as a plasma membrane protein. J Biol Chem 273:15590-15597.

Hägg P, Väisänen T, Tuomisto A, Rehn M, Tu H, Huhtala P, Eskelinen S, Pihlajaniemi T. 2001. Type XIII collagen: a novel cell adhesion component present in a range of cellmatrix adhesions and in the intercalated discs between cardiac muscle cells. Matrix Biol 19:727-742.

Hall ZW, Sanes JR. 1993. Synaptic structure and development: the neuromuscular junction. Cell 72 Suppl:99-121.

Hantai D, Nicole S, Eymard B. 2013. Congenital myasthenic syndromes: an update. Curr Opin Neurol 26:561-568.

Härönen H, Zainul Z, Tu H, Naumenko N, Sormunen R, Miinalainen I, Shakirzyanova A, Oikarainen T, Abdullin A, Martin P, Santoleri S, Koistinaho J, Silmanl I, Giniatullin R, Fox MA, Heikkinen A, Pihlajaniemi T. 2017. Collagen XIII secures pre- and postsynaptic integrity of the neuromuscular synapse. Hum Mol Genet 26:2076-2090.

Hashimoto T, Wakabayashi T, Watanabe A, Kowa H, Hosoda R, Nakamura A, Kanazawa I, Arai T, Takio K, Mann DM, Iwatsubo T. 2002. CLAC: a novel Alzheimer amyloid plaque component derived from a transmembrane precursor, CLAC-P/collagen type XXV. EMBO J 21:1524-1534.

Hulsbrink R, Hashemolhosseini S. 2014. Lambert-Eaton myasthenic syndrome - diagnosis, pathogenesis and therapy. Clin Neurophysiol 125:2328-2336.

Huze C, Bauche S, Richard P, Chevessier F, Goillot E, Gaudon K, Ben Ammar A, Chaboud A, Grosjean I, Lecuyer HA, Bernard V, Rouche A, Alexandri N, Kuntzer T, Fardeau M, Fournier E, Brancaccio A, Rüegg MA, Koenig J, Eymard B, Schaeffer L, Hantai D. 2009. Identification of an agrin mutation that causes congenital myasthenia and affects synapse function. Am J Hum Genet 85:155-167.

Jacobson C, Cote PD, Rossi SG, Rotundo RL, Carbonetto S. 2001. The dystroglycan complex is necessary for stabilization of acetylcholine receptor clusters at neuromuscular junctions and formation of the synaptic basement membrane. J Cell Biol 152:435-450.

Jones RA, Harrison C, Eaton SL, Llavero Hurtado M, Graham LC, Alkhammash L, Oladiran OA, Gale A, Lamont DJ, Simpson H, Simmen MW, Soeller C, Wishart TM, Gillingwater TH. 2017. Cellular and Molecular Anatomy of the Human Neuromuscular Junction. Cell Rep 21:2348-2356.

Karakaya M, Ceyhan-Birsoy O, Beggs AH, Topaloglu H. 2017. A Novel Missense Variant in the AGRN Gene; Congenital Myasthenic Syndrome Presenting With Head Drop. J Clin Neuromuscul Dis 18:147-151.

Karmouch J, Dobbertin A, Sigoillot S, Legay C. 2013. Developmental consequences of the ColQ/MuSK interactions. Chem Biol Interact 203:287-291.

This article is protected by copyright. All rights reserved. 
Khan AO, Al-Mesfer S. 2015. Recessive COL25A1 mutations cause isolated congenital ptosis or exotropic Duane syndrome with synergistic divergence. J AAPOS 19:463465.

Kimbell LM, Ohno K, Engel AG, Rotundo RL. 2004. C-terminal and heparin-binding domains of collagenic tail subunit are both essential for anchoring acetylcholinesterase at the synapse. J Biol Chem 279:10997-11005.

Knight D, Tolley LK, Kim DK, Lavidis NA, Noakes PG. 2003. Functional analysis of neurotransmission at beta2-laminin deficient terminals. J Physiol 546:789-800.

Krejci E, Thomine S, Boschetti N, Legay C, Sketelj J, Massoulie J. 1997. The mammalian gene of acetylcholinesterase-associated collagen. J Biol Chem 272:22840-22847.

Latvanlehto A, Fox MA, Sormunen R, Tu H, Oikarainen T, Koski A, Naumenko N, Shakirzyanova A, Kallio M, Ilves M, Giniatullin R, Sanes JR, Pihlajaniemi T. 2010. Muscle-derived collagen XIII regulates maturation of the skeletal neuromuscular junction. J Neurosci 30:12230-12241.

Law PK, Saito A, Fleischer S. 1983. Ultrastructural changes in muscle and motor end-plate of the dystrophic mouse. Exp Neurol 80:361-382.

Lee M, Beeson D, Palace J. 2018. Therapeutic strategies for congenital myasthenic syndromes. Ann N Y Acad Sci 1412:129-136.

Li Y, Lee Y, Thompson WJ. 2011. Changes in aging mouse neuromuscular junctions are explained by degeneration and regeneration of muscle fiber segments at the synapse. J Neurosci 31:14910-14919.

Liang CL, Han S. 2013. Neuromuscular junction disorders. PM R 5:S81-8.

Lin W, Burgess RW, Dominguez B, Pfaff SL, Sanes JR, Lee KF. 2001. Distinct roles of nerve and muscle in postsynaptic differentiation of the neuromuscular synapse. Nature 410:1057-1064.

Liu Y, Padgett D, Takahashi M, Li H, Sayeed A, Teichert RW, Olivera BM, McArdle JJ, Green WN, Lin W. 2008. Essential roles of the acetylcholine receptor gamma-subunit in neuromuscular synaptic patterning. Development 135:1957-1967.

Logan CV, Cossins J, Rodriguez Cruz PM, Parry DA, Maxwell S, Martinez-Martinez P, Riepsaame J, Abdelhamed ZA, Lake AV, Moran M, Robb S, Chow G, Sewry C, Hopkins PM, Sheridan E, Jayawant S, Palace J, Johnson CA, Beeson D. 2015. Congenital Myasthenic Syndrome Type 19 Is Caused by Mutations in COL13A1, Encoding the Atypical Non-fibrillar Collagen Type XIII alphal Chain. Am J Hum Genet 97:878-885.

Lorenzoni PJ, Scola RH, Kay CS, Werneck LC. 2012. Congenital myasthenic syndrome: a brief review. Pediatr Neurol 46:141-148.

Martin PT, Kaufman SJ, Kramer RH, Sanes JR. 1996. Synaptic integrins in developing, adult, and mutant muscle: selective association of alpha1, alpha7A, and alpha7B integrins with the neuromuscular junction. Dev Biol 174:125-139. 
Maselli RA, Arredondo J, Ferns MJ, Wollmann RL. 2012. Synaptic basal lamina-associated congenital myasthenic syndromes. Ann N Y Acad Sci 1275:36-48.

Maselli RA, Arredondo J, Vazquez J, Chong JX, Bamshad MJ, Nickerson DA, Lara M, Ng F, Lo VL, Pytel P, McDonald CM. 2018. A presynaptic congenital myasthenic syndrome attributed to a homozygous sequence variant in LAMA5. Ann N Y Acad Sci 1413:119-125.

Maselli RA, Arredondo J, Vazquez J, Chong JX, University of Washington Center for Mendelian Genomics, Bamshad MJ, Nickerson DA, Lara M, Ng F, Lo VL, Pytel P, McDonald CM. 2017. Presynaptic congenital myasthenic syndrome with a homozygous sequence variant in LAMA5 combines myopia, facial tics, and failure of neuromuscular transmission. Am J Med Genet A 173:2240-2245.

Maselli RA, Fernandez JM, Arredondo J, Navarro C, Ngo M, Beeson D, Cagney O, Williams DC, Wollmann RL, Yarov-Yarovoy V, Ferns MJ. 2012. LG2 agrin mutation causing severe congenital myasthenic syndrome mimics functional characteristics of non-neural (z-) agrin. Hum Genet 131:1123-1135.

Maselli RA, Ng JJ, Anderson JA, Cagney O, Arredondo J, Williams C, Wessel HB, AbdelHamid H, Wollmann RL. 2009. Mutations in LAMB2 causing a severe form of synaptic congenital myasthenic syndrome. J Med Genet 46:203-208.

Massoulie J, Millard CB. 2009. Cholinesterases and the basal lamina at vertebrate neuromuscular junctions. Curr Opin Pharmacol 9:316-325.

Matejas V, Hinkes B, Alkandari F, Al-Gazali L, Annexstad E, Aytac MB, Barrow M, Blahova K, Bockenhauer D, Cheong HI, Maruniak-Chudek I, Cochat P, Dotsch J, Gajjar P, Hennekam RC, Janssen F, Kagan M, Kariminejad A, Kemper MJ, Koenig J, Kogan J, Kroes HY, Kuwertz-Broking E, Lewanda AF, Medeira A, Muscheites J, Niaudet P, Pierson M, Saggar A, Seaver L, Suri M, Tsygin A, Wuhl E, Zurowska A, Uebe S, Hildebrandt F, Antignac C, Zenker M. 2010. Mutations in the human laminin beta2 (LAMB2) gene and the associated phenotypic spectrum. Hum Mutat 31:9921002.

Miner JH, Cunningham J, Sanes JR. 1998. Roles for laminin in embryogenesis: exencephaly, syndactyly, and placentopathy in mice lacking the laminin alpha5 chain. J Cell Biol 143:1713-1723.

Miyagoe-Suzuki Y, Nakagawa M, Takeda S. 2000. Merosin and congenital muscular dystrophy. Microsc Res Tech 48:181-191.

Montanaro F, Gee SH, Jacobson C, Lindenbaum MH, Froehner SC, Carbonetto S. 1998. Laminin and alpha-dystroglycan mediate acetylcholine receptor aggregation via a MuSK-independent pathway. J Neurosci 18:1250-1260.

Nishimune H, Sanes JR, Carlson SS. 2004. A synaptic laminin-calcium channel interaction organizes active zones in motor nerve terminals. Nature 432:580-587.

Nishimune H, Stanford JA, Mori Y. 2014. Role of exercise in maintaining the integrity of the neuromuscular junction. Muscle Nerve 49:315-324.

This article is protected by copyright. All rights reserved. 
Nishimune H, Valdez G, Jarad G, Moulson CL, Muller U, Miner JH, Sanes JR. 2008. Laminins promote postsynaptic maturation by an autocrine mechanism at the neuromuscular junction. J Cell Biol.

Noakes PG, Gautam M, Mudd J, Sanes JR, Merlie JP. 1995. Aberrant differentiation of neuromuscular junctions in mice lacking s-laminin/laminin beta 2. Nature 374:258262.

Nykvist P, Tu H, Ivaska J, Kapyla J, Pihlajaniemi T, Heino J. 2000. Distinct recognition of collagen subtypes by alpha(1)beta(1) and alpha(2)beta(1) integrins. Alpha(1)beta(1) mediates cell adhesion to type XIII collagen. J Biol Chem 275:8255-8261.

Ohno K, Brengman J, Tsujino A, Engel AG. 1998. Human endplate acetylcholinesterase deficiency caused by mutations in the collagen-like tail subunit (ColQ) of the asymmetric enzyme. Proc Natl Acad Sci U S A 95:9654-9659.

Ohno K, Brengman JM, Felice KJ, Cornblath DR, Engel AG. 1999. Congenital end-plate acetylcholinesterase deficiency caused by a nonsense mutation and an A-- $>$ G splicedonor-site mutation at position +3 of the collagenlike-tail-subunit gene (COLQ): how does $\mathrm{G}$ at position +3 result in aberrant splicing?. Am J Hum Genet 65:635-644.

Parr JR, Andrew MJ, Finnis M, Beeson D, Vincent A, Jayawant S. 2014. How common is childhood myasthenia? The UK incidence and prevalence of autoimmune and congenital myasthenia. Arch Dis Child 99:539-542.

Patton BL. 2003. Basal lamina and the organization of neuromuscular synapses. J Neurocytol 32:883-903.

Patton BL, Chiu AY, Sanes JR. 1998. Synaptic laminin prevents glial entry into the synaptic cleft. Nature 393:698-701.

Patton BL, Cunningham JM, Thyboll J, Kortesmaa J, Westerblad H, Edstrom L, Tryggvason K, Sanes JR. 2001. Properly formed but improperly localized synaptic specializations in the absence of laminin alpha4. Nat Neurosci 4:597-604.

Patton BL, Miner JH, Chiu AY, Sanes JR. 1997. Distribution and function of laminins in the neuromuscular system of developing, adult, and mutant mice. J Cell Biol 139:15071521.

Peng HB, Xie H, Rossi SG, Rotundo RL. 1999. Acetylcholinesterase clustering at the neuromuscular junction involves perlecan and dystroglycan. J Cell Biol 145:911-921.

Perrot R, Eyer J. 2009. Neuronal intermediate filaments and neurodegenerative disorders. Brain Res Bull 80:282-295.

Punga AR, Rüegg MA. 2012. Signaling and aging at the neuromuscular synapse: lessons learnt from neuromuscular diseases. Curr Opin Pharmacol 12:340-346.

Rodriguez Cruz PM, Palace J, Beeson D. 2014a. Congenital myasthenic syndromes and the neuromuscular junction. Curr Opin Neurol 27:566-575.

Rodriguez Cruz PM, Palace J, Beeson D. 2014b. Inherited disorders of the neuromuscular junction: an update. J Neurol 261:2234-2243.

This article is protected by copyright. All rights reserved. 
Ross JA, Webster RG, Lechertier T, Reynolds LE, Turmaine M, Bencze M, Jamshidi Y, Cetin H, Muntoni F, Beeson D, Hodilvala-Dilke K, Conti FJ. 2017. Multiple roles of integrin-alpha3 at the neuromuscular junction. J Cell Sci 130:1772-1784.

Samuel MA, Valdez G, Tapia JC, Lichtman JW, Sanes JR. 2012. Agrin and synaptic laminin are required to maintain adult neuromuscular junctions. PLoS One 7:e46663.

Sanes JR. 2003. The basement membrane/basal lamina of skeletal muscle. J Biol Chem 278:12601-12604.

Sanes JR, Engvall E, Butkowski R, Hunter DD. 1990. Molecular heterogeneity of basal laminae: isoforms of laminin and collagen IV at the neuromuscular junction and elsewhere. J Cell Biol 111:1685-1699.

Sanes JR, Lichtman JW. 2001. Induction, assembly, maturation and maintenance of a postsynaptic apparatus. Nat Rev Neurosci 2:791-805.

Sanes JR, Lichtman JW. 1999. Development of the vertebrate neuromuscular junction. Annu Rev Neurosci 22:389-442.

Shi L, Fu AK, Ip NY. 2012. Molecular mechanisms underlying maturation and maintenance of the vertebrate neuromuscular junction. Trends Neurosci 35:441-453.

Shinwari JM, Khan A, Awad S, Shinwari Z, Alaiya A, Alanazi M, Tahir A, Poizat C, Al Tassan N. 2015. Recessive mutations in COL25A1 are a cause of congenital cranial dysinnervation disorder. Am J Hum Genet 96:147-152.

Sieb JP. 2014. Myasthenia gravis: an update for the clinician. Clin Exp Immunol 175:408418.

Sigoillot SM, Bourgeois F, Karmouch J, Molgo J, Dobbertin A, Chevalier C, Houlgatte R, Leger J, Legay C. 2016. Neuromuscular junction immaturity and muscle atrophy are hallmarks of the ColQ-deficient mouse, a model of congenital myasthenic syndrome with acetylcholinesterase deficiency. FASEB J 30:2382-2399.

Sigoillot SM, Bourgeois F, Lambergeon M, Strochlic L, Legay C. 2010. ColQ controls postsynaptic differentiation at the neuromuscular junction. J Neurosci 30:13-23.

Singhal N, Martin PT. 2011. Role of extracellular matrix proteins and their receptors in the development of the vertebrate neuromuscular junction. Dev Neurobiol 71:982-1005.

Souza PV, Batistella GN, Lino VC, Pinto WB, Annes M, Oliveira AS. 2016. Clinical and genetic basis of congenital myasthenic syndromes. Arq Neuropsiquiatr 74:750-760.

Spillane J, Beeson DJ, Kullmann DM. 2010. Myasthenia and related disorders of the neuromuscular junction. J Neurol Neurosurg Psychiatry 81:850-857.

Sund M, Väisänen T, Kaukinen S, Ilves M, Tu H, Autio-Harmainen H, Rauvala H, Pihlajaniemi T. 2001. Distinct expression of type XIII collagen in neuronal structures and other tissues during mouse development. Matrix Biol 20:215-231.

Talts JF, Andac Z, Gohring W, Brancaccio A, Timpl R. 1999. Binding of the G domains of laminin alpha1 and alpha2 chains and perlecan to heparin, sulfatides, alphadystroglycan and several extracellular matrix proteins. EMBO J 18:863-870.

This article is protected by copyright. All rights reserved. 
Tanaka T, Wakabayashi T, Oizumi H, Nishio S, Sato T, Harada A, Fujii D, Matsuo Y, Hashimoto T, Iwatsubo T. 2014. CLAC-P/Collagen Type XXV Is Required for the Intramuscular Innervation of Motoneurons during Neuromuscular Development. J Neurosci 34:1370-1379.

Taylor J, Unsoeld T, Hutter H. 2018. The transmembrane collagen COL-99 guides longitudinally extending axons in C. elegans. Mol Cell Neurosci 89:9-19.

Tintignac LA, Brenner HR, Rüegg MA. 2015. Mechanisms Regulating Neuromuscular Junction Development and Function and Causes of Muscle Wasting. Physiol Rev 95:809-852.

Tu H, Huhtala P, Lee HM, Adams JC, Pihlajaniemi T. 2015. Membrane-associated collagens with interrupted triple-helices (MACITs): evolution from a bilaterian common ancestor and functional conservation in C. elegans. BMC Evol Biol 15:281015-0554-3.

Tu H, Pirskanen-Matell R, Heikkinen A, Oikarainen T, Risteli J, Pihlajaniemi T. 2018. Autoimmune antibodies to collagen XIII in myasthenia gravis patients. Muscle Nerve 57:506-510.

Tu H, Sasaki T, Snellman A, Gohring W, Pirilä P, Timpl R, Pihlajaniemi T. 2002. The type XIII collagen ectodomain is a 150-nm rod and capable of binding to fibronectin, nidogen-2, perlecan, and heparin. J Biol Chem 277:23092-23099.

Vainzof M, Ayub-Guerrieri D, Onofre PC, Martins PC, Lopes VF, Zilberztajn D, Maia LS, Sell K, Yamamoto LU. 2008. Animal models for genetic neuromuscular diseases. J Mol Neurosci 34:241-248.

Väisänen MR, Väisänen T, Pihlajaniemi T. 2004. The shed ectodomain of type XIII collagen affects cell behaviour in a matrix-dependent manner. Biochem $\mathrm{J}$ 380:685693.

Valdez G, Tapia JC, Kang H, Clemenson GD,Jr, Gage FH, Lichtman JW, Sanes JR. 2010. Attenuation of age-related changes in mouse neuromuscular synapses by caloric restriction and exercise. Proc Natl Acad Sci U S A 107:14863-14868.

Veit G, Zimina EP, Franzke CW, Kutsch S, Siebolds U, Gordon MK, Bruckner-Tuderman L, Koch M. 2007. Shedding of collagen XXIII is mediated by furin and depends on the plasma membrane microenvironment. J Biol Chem 282:27424-27435.

Webster RG. 2018. Animal Models of the Neuromuscular Junction, Vitally Informative for Understanding Function and the Molecular Mechanisms of Congenital Myasthenic Syndromes. Int J Mol Sci 19:10.3390/ijms19051326.

$\mathrm{Wu} \mathrm{H}$, Xiong WC, Mei L. 2010. To build a synapse: signaling pathways in neuromuscular junction assembly. Development 137:1017-1033.

Xie W, Stribley JA, Chatonnet A, Wilder PJ, Rizzino A, McComb RD, Taylor P, Hinrichs SH, Lockridge O. 2000. Postnatal developmental delay and supersensitivity to organophosphate in gene-targeted mice lacking acetylcholinesterase. J Pharmacol Exp Ther 293:896-902.

This article is protected by copyright. All rights reserved 
Yang Y, Coleman M, Zhang L, Zheng X, Yue Z. 2013. Autophagy in axonal and dendritic degeneration. Trends Neurosci 36:418-428.

Zainul Z, Heikkinen A, Koivisto H, Rautalahti I, Kallio M, Lin S, Härönen H, Norman O, Rüegg MA, Tanila H, Pihlajaniemi T. 2018. Collagen XIII Is Required for Neuromuscular Synapse Regeneration and Functional Recovery after Peripheral Nerve Injury. J Neurosci 38:4243-4258.

Zhang B, Luo S, Wang Q, Suzuki T, Xiong WC, Mei L. 2008. LRP4 serves as a coreceptor of agrin. Neuron 60:285-297.

Zhang W, Coldefy AS, Hubbard SR, Burden SJ. 2011. Agrin binds to the N-terminal region of Lrp4 protein and stimulates association between Lrp4 and the first immunoglobulin-like domain in muscle-specific kinase (MuSK). J Biol Chem 286:40624-40630.

Zhang Y, Dai Y, Han JN, Chen ZH, Ling L, Pu CQ, Cui LY, Huang XS. 2017. A Novel AGRN Mutation Leads to Congenital Myasthenic Syndrome Only Affecting Limbgirdle Muscle. Chin Med J (Engl) 130:2279-2282.

\section{FIGURE LEGENDS}

Figure 1. Structure and temporal aspects of the neuromuscular system in mice. A) The motor nerve terminal, capped by terminal Schwann cells covered by a kranocyte and with the axon myelinated by Schwann cells, encloses cytoskeletal structures, mitochondria, synaptic vesicles, active zones, and other components. AChE resides in the synaptic cleft, embedded in the sheetlike BL. The postsynaptic muscle sarcolemma forms secondary junctional folds from the primary synaptic cleft. Preterminally released ACh diffuses through that cleft and is bound by AChRs clustered on the crest of secondary folds opposite active zones, resulting in contraction of crossstriated myofibrils. B-C) Embryonally (E), ECM cues guide motoneuron axons associated with Schwann cells toward prepatterned AChR clusters, some of which become innervated by

This article is protected by copyright. All rights reserved. 
multiple axons while others remain without innervation. The latter disappear before birth, whereas innervated clusters postnatally $(\mathrm{P})$ become singly innervated and myelinated, achieving mature, pretzel-like shape by P28. Several muscle fibers with shared metabolic and function properties (slow- and fast-twitch fibers, in red and green) are innervated by a single motor nerve, thereby jointly forming a motor unit. Among the indicators of eroding NMJ integrity in aging and disease are preterminal retraction, sprouting, and swallowing and postsynaptic rarefying, dispersion, and fragmentation of AChR clusters.

Figure 2. Molecular assembly of the motor synapse. The agrin-MuSK-Lrp4 complex contributes to AChR clustering. Laminins are presented here with their presynaptic and postsynaptic receptors. Synaptic interactions of collagens IV, VI, and XIII; nidogen-2; perlecan; and ColQ further stabilize the synapse. 


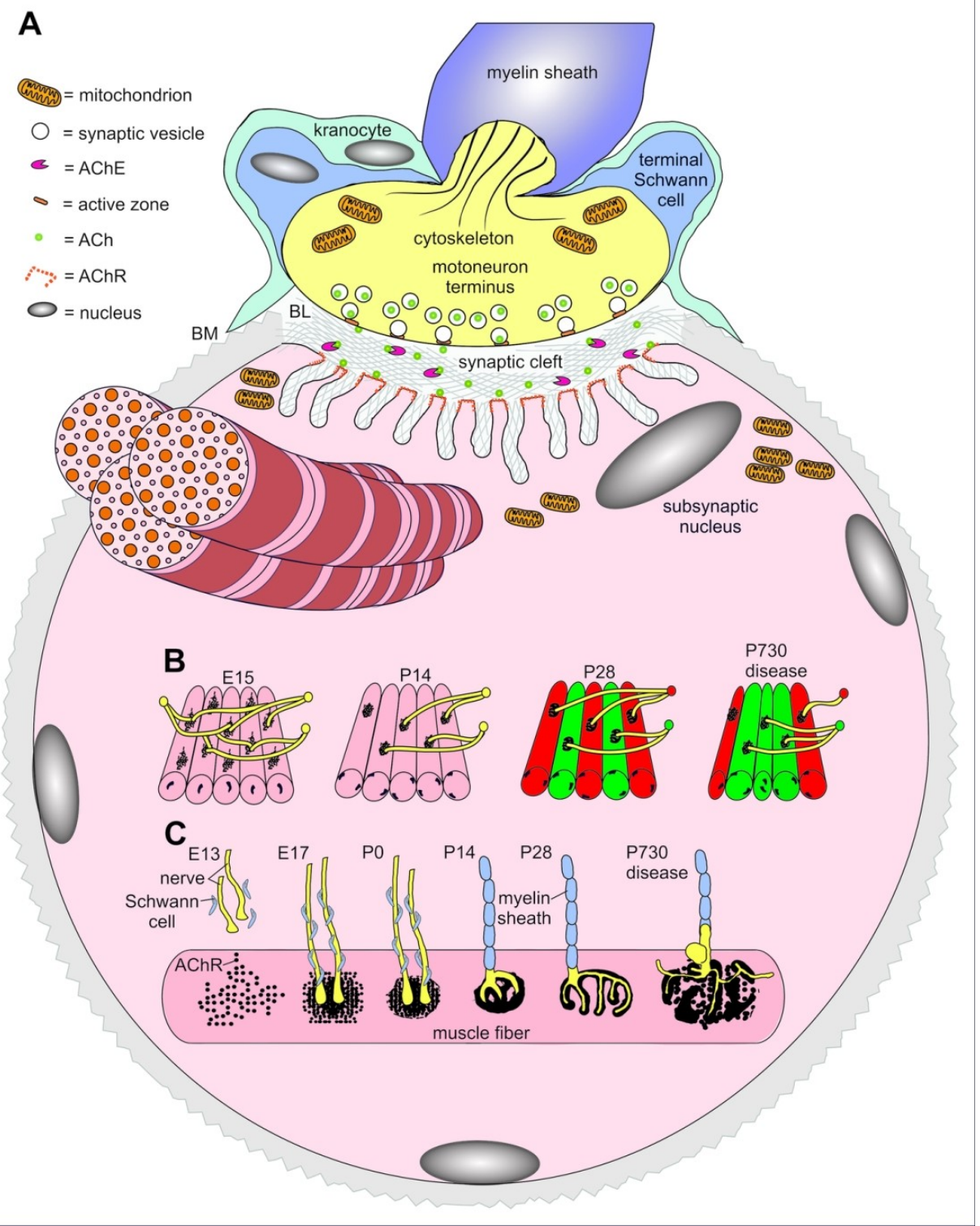

This article is protected by copyright. All rights reserved. 


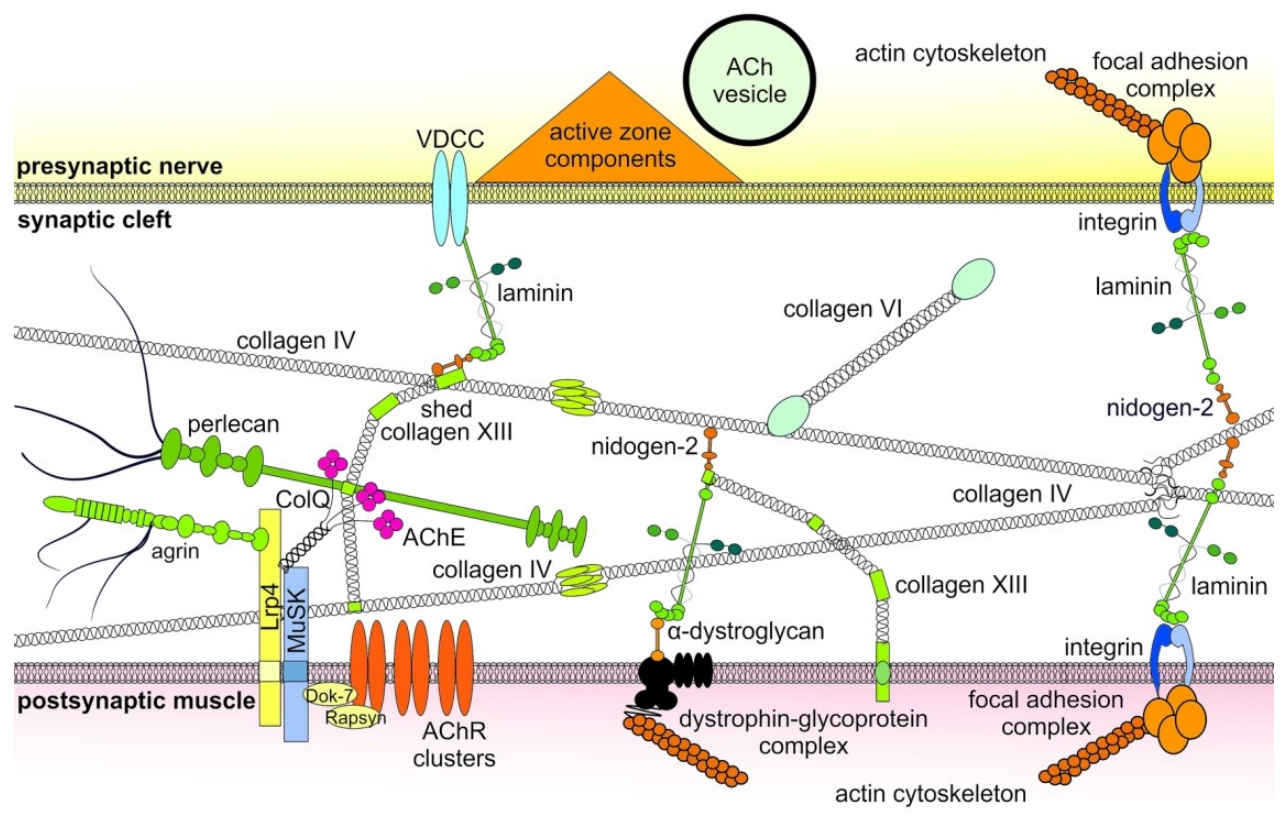

This article is protected by copyright. All rights reserved. 